$\xi=-1$

\title{
Synthesis of Hydrophobic Filler for Polymer Composites
}

\author{
V.I. Pavlenko*, N.I. Cherkashina \\ Belgorod State Technological University Named After V.G. Shoukhov, Belgorod, 308012, Kostyukov Str., 46, Russia \\ *Corresponding Author E-Mail: Cherkashina.Ni@Bstu.Ru
}

\begin{abstract}
Silica ( $\mathrm{SiO} 2)$ particles are increasingly more used for the productions of polymer composites. But introduction of silica in polymer disturbs the natural structure uniformity also this technique is difficult with the aid of the high propensity of silica to agglomeration. So to create polymer composites it is better to use fillers with a hydrophobic surface. In this study, it was investigated the possibility of surface amendment of Silica particles for their hydrophobization. Silica particles had been organized by way of the tetraethyl orthosilicate hydrolysis reaction at high temperature and pressure. The morphology and shape of the silica were studied by way of X-ray powder diffraction, approach of particle measurement analysis by using laser diffraction, and electron micrograph. For floor amendment of silica particles was use hydroalcoholic answer of sodium methylsiliconate. The bought results of the contact perspective measurements show that the floor of initial particles of silica is hydrophilic (contact perspective $-74^{\circ}$ ). The surface of Silica particles after the change are strongly hydrophobic (contact angle $-92-126^{\circ}$ ). The most suitable is the introduction of a modifier in an amount of $2 \%$.
\end{abstract}

Keywords: Silica particles, Contact angle, Hydrophobization, Hydrothermal treatment, Modifying

\section{Introduction}

Currently, polymer composites have been observed huge utility in different industries, such as automotive, military, medical, aerospace and energy. Polymer composites are normally natural polymer composites typically crammed with distinct fillers. Their residences combine the advantages of the inorganic filler cloth (i. e., electro-optical, photoconductivity, magnetic and dielectric properties) and of the natural polymer (i. e., fluidity, viscoelasticity, elasticity). Of specific pastime are polymer composites with silica [1-6]. Alnamel et al. has shown that the addition of Silica powder to acrylic resin improves the have an effect on power and transverse power of acrylic resin [7]. Hsieh et al. has set up that the fracture electricity of the bulk epoxy perhaps multiplied from 77 to $212 \mathrm{~J} / \mathrm{m} 2$ with the aid of the addition of $20 \mathrm{wt} . \%$ silica nanoparticles [8].

The presence of silica nanoparticles (4.5 wt.\%) in the polypropylene-Silica nanocomposites leads to an extend of each Young modulus and impact strength, from 1.2 GPa to $1.6 \mathrm{GPa}$ and from $3.4 \mathrm{~kJ} / \mathrm{m}^{2}$ to $5.7 \mathrm{~kJ} / \mathrm{m}^{2}$ respectively [9].

Introduction of filler Silica in polymer disturbs the polymer matrix uniformity. Interaction of fine-dispersed strong particles with a pol-ymer is eastimated via homogeneity degree of particles and polymer adhesion to their surface [10]. It is very tough to resolve such a hassle by way of conventional strategies of mixing of particles Silica and polymer, considering that this technique is intricate by way of the excessive propensity of Silica to agglomeration. Homogeneity diploma of Silica particles and polymer adhesion depend on physico-mechanical properties of Silica particle surface. To enhance the dispersion and compatibility of nanofiller in the polymer matrix, in many instances its floor is modified [11-15], which leads no longer only to improvement of the filler distribution in the polymer matrix, but additionally affords a possibility of their chemical interaction, ensuring a strong chemical bond between two incompatible phases.

To create polymer composites it is better to use fillers with a hydro-phobic surface. Benefits of fillers with a hydrophobic surface include accelerated dispersion of the fillers into polymeric media, decrease viscosity of the mix, larger compatibility with the polymer, improved electrical properties in a mineral-filled polymer system, and accelerated cure of thermoset polymers in contact with the mineral surface [16]. The surface is called hydrophilic, if the contact angle between liquid and strong surface is much less than $90^{\circ}$, in any other case the floor is referred to as hydrophobic (fig. 1) [17].

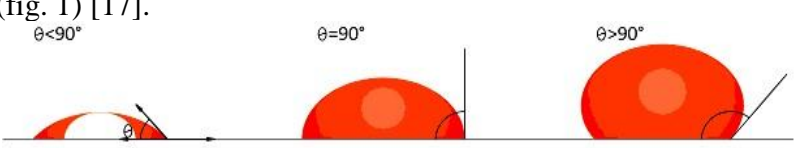

Fig. 1: Schematic diagram of contact angle

The floor of Silica particles is polar, and organic modifier surfacing is essential for its hydrophobization for enhance particle distribution in matrix and lets inloading the maximum quantity of filler in the polymer. The strategies utilized for education of hydrophobic surfaces consist of the introduction of nanoroughness onto a low floor energy fabric and then decrease its floorenergy, by means of chemical modification [18-23].

This work gives the opportunity of floor change of silica particles for their hydrophobization. Silica particles were once synthesized using by way of the tetraethyl orthosilicate (tetraethoxysilane or TEOS) hydrolysis response at hydrothermal treatment.

\section{Material and Methods}

\subsection{Materials}


In this synthesis procedure, we use tetraethyl orthosilicate used to be purchased from Vitohim Ltd., St. Petersburg, Russia (99.9 p.c purity). Tetraethyl orthosilicate (TEOS) is the chemical compound with the method $\mathrm{SiC}_{8} \mathrm{H}_{20} \mathrm{O}_{4}$. The Silica particles had been got through TEOS hydrolysis reaction at temperature $300^{\circ} \mathrm{C}$ and pressure $55 \mathrm{MPa}$ for 7 hours, observed with the aid of dried at a temperature of $110-120^{\circ} \mathrm{C}$.

For surface change of Silica particles we use hydroalcoholic solution of sodium methylsiliconate (30\% aqueous solution) with the components $\mathrm{CH}_{5} \mathrm{SiO}_{3} \mathrm{Na}$ was bought from Vitohim Ltd., St. Petersburg, Russia.

\subsection{Research Methods}

The lookup used to be performed using tools of Center for radiation monitoring and the Department of theoretical and applied chem-istry of BSTU named after V.G. Shukhov (Belgorod, Russia). ANALYSETTE 22 NanoTec used to be used for Silica particles measurement analysis. Analysette 22 NanoTec has a extensive vary of particle measurement measurements. The decrease limit of dimension is about $0.01 \mu \mathrm{m}$.

ANALYSETTE 22 NanoTec plus lets in you to pick out three posi-tions of the measuring cell, which, except adjustment, permit meas-urement in 5 exclusive ranges.

The segment analyses have been carried out by using X-ray diffraction method using the DRON-3 diffractometer. The DRON-3 diffrac-tometer having the following operation parameters: $U=20$ $\mathrm{kV}, \mathrm{I}=20 \mathrm{~mA}$, and $\mathrm{X}$-ray tube furnished with $\mathrm{Cu}$ goal and a mono-chromator in X-ray diffracted beam, has been used.

Scanning (raster) digital microscopy was once used for the floor morphology identification and microanalysis of the floor layer of the Silica particles. Microphotography was performed the use of elec-tronic microscope Tescan Mira 3 LMU.

The following approach for identifying contact angle: on the substrate a layer of the powder to be studied is positioned in a skinny layer. A drop of liquid ( $2 \mathrm{ml})$ is distributed onto the substrate. The silhouette of the drop is seen through a digital camera connected to a PC to seize video photographs of the drop. Image analysis software is used to calcu-late the contact angle. Water drop contact perspective measurements are made using distilled water. The attitude is determined 1 second after the drop is positioned on the substrate surface.

\section{Results and Discussion}

Figure 2 shows the X-ray diffractogram (XRD) of the product synthesized by using the TEOS hydrolysis response at hydrothermal treatment. The crystalline phase were recognized the usage of the JCPDS (2000). The analysis of the XRD sample shows that the product is shaped by way of the crystalline segment quartz (Silica - JCPDS 46-1045).

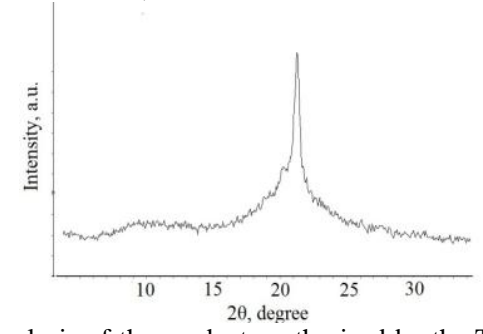

Fig. 2: XRD analysis of the product synthesized by the TEOS hydrolysis reaction at hydrothermal treatment

Figure 3 indicates scanning electron microscopy (SEM) photo for Silica particles acquired by way of TEOS hydrolysis response at hydrother-mal treatment. They are predominantly person particles of trian-gular or hexagonal shape.

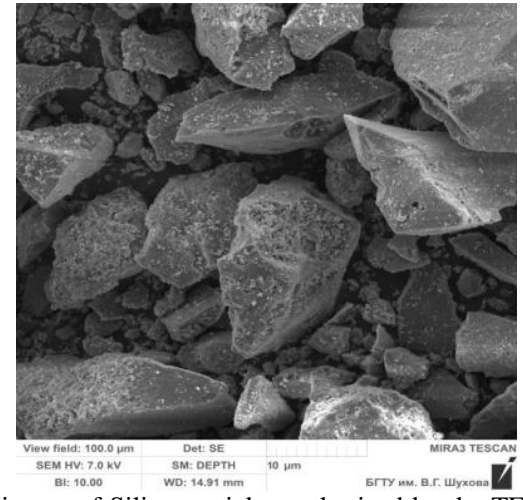

Fig. 3: SEM image of Silica particle synthesized by the TEOS hydrolysis reaction at hydrothermal treatment

The differential Silica particle size histogram (figure 4) shows a size range from $0.1 \mathrm{mkm}$ to $10 \mathrm{mkm}$.

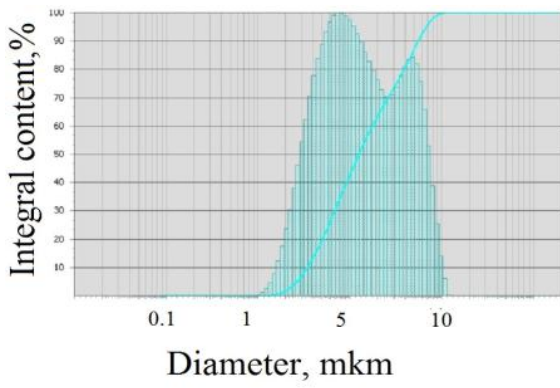

Fig. 4: Silica particle size distribution

Samples of Silica particles had been modified via sodium methylsiliconate. To precipitate $\mathrm{OH}$ - companies on the floor of Silica particles, moist milling, boiling and sonication $(22 \mathrm{~Hz})$ were performed. After all, the product used to be dried at one hundred twenty ${ }^{\circ} \mathrm{C}$ The fixing of $\mathrm{OH}$-groups on the floor of Silica particles two proceeds in accordance to scheme:

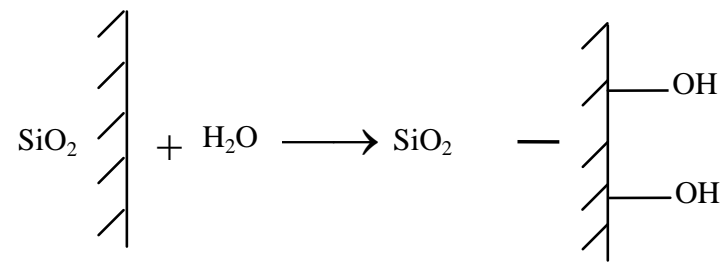

After elimination of the solvent from the product, it is essential to carry out the polymerization of the modifier at a temperature of a hundred and sixty ${ }^{\circ} \mathrm{C}$ for 10 minutes. The amendment response proceeds according to the following scheme:

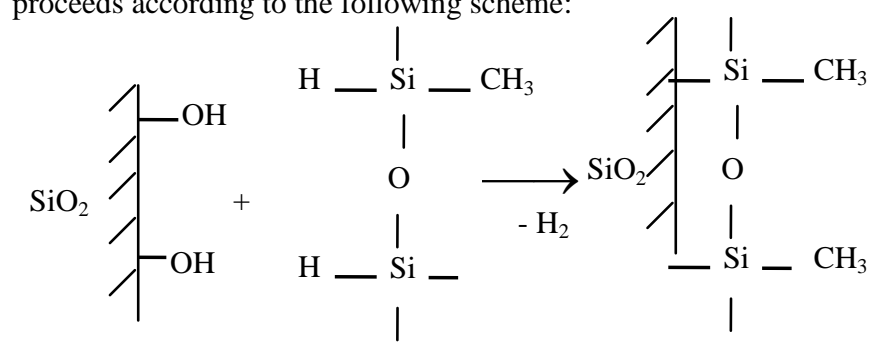

Table 1 shows contact angles of Silica particles before and after the modification.

Table 1: Contact angles of Silica particles

\begin{tabular}{|c|c|}
\hline Modifier content, $\%$ & Contact angle, ${ }^{\circ}$ (degrees) \\
\hline- & 74 \\
0,5 & 92 \\
1 & 115 \\
2 & 126 \\
3 & 126 \\
4 & 126 \\
5 & 126 \\
\hline
\end{tabular}


The acquired effects of the contact attitude measurements exhibit that the floor of preliminary Silica particles is two hydrophilic (contact attitude - two $74^{\circ}$ ). The surface of Silica particles after the modification are strongly hydrophobic (contact angle - 92$126^{\circ}$ ). Analysis of the records in Table 1 showed that the greatest is the introduction of a modifier in an quantity of $2 \%$. With a smaller amount of modifier, the wetting angle is much lower. When more than $2 \%$ of the modifier is introduced, the wetting perspective does now not change and is equal to $126^{\circ}$.

\section{Conclusion}

The experimental results mentioned in this paper published that samples of Silica particles should be modified by sodium methylsiliconate. Silica particles used to be synthesized the use of by means of the tetraethyl orthosilicate (tetraethoxysilane or TEOS) hydrolysis response at hydrothermal treatment. The analysis of the XRD sample allowed us to establish that the product is shaped via the crystalline section quartz. The differential Silica particle measurement histogram two showed a dimension vary from 0.1 $\mathrm{mkm}$ to $10 \mathrm{mkm}$. The received consequences of the contact angle measurements exhibit that the surface of initial Silica particles is two hydrophilic (contact perspective - two $74^{\circ}$ ). The surface of silica particles after the modification are strongly hydrophobic (contact perspective $-92-126^{\circ}$ ). Authors mounted that the topquality is the addition of a modifier in an amount of $2 \%$.

\section{Acknowledgement}

The work is executed at support of Russian Science Foundation (project № 17-79-10075).

\section{References}

[1] D.W. Lee, B.R. Yoo (2016), Advanced silica/polymer composites: Materials and applications. Journal of Industrial and Engineering Chemistry. 38, 1-12.

[2] P. Krasucka, W. Stefaniak, A. Kierys, J. Goworek (2016), Polymersilica composites and silicas produced by high-temperature degradation of organic component, Thermochimica. Acta 615, 43-50.

[3] M. Conradi (2013), Nanosilica-reinforced polymer composites, $\mathrm{Ma}$ terials and technology 47, 285-293.

[4] M. Marrone, T. Montanari, G. Busca, L. Conzatti, G. Costa, M. Castellano, A. Turturro (2004), A Fourier transform infrared (FTIR) study of the reaction of triethoxysilane (TES) and bis [3triethoxysilylpropyl] tetrasulfane (TESPT) with the surface of amorphous silica, The Journal of Physical Chemistry B 108, 3563 3572 .

[5] M.M. Kulkarni, R. Bandyopadhyaya, Bi. Bhattacharya, A. Sharma (2006), Microstructural and mechanical properties of silica-PEPEG polymer composite xerogels, Acta Materialia 54, 5231-5240.

[6] G. Liu, H. Zhang, X. Yang, Y. Wang (2009), Facile synthesis of functional silica/polymer composite materials and hydrophilic hollow polymer microspheres, Journal of Applied Polymer Science 111, 1964-1975.

[7] H.A. Alnamel, M. Mudhaffer (2014), The effect of Silicon di oxide Nano -Fillers reinforcement on some properties of heat cure polymethyl methacrylate denture base material, J. Bagh. Coll. Dentistry 26, 32-36.

[8] T.H. Hsieh, A.J. Kinloch, K. Masania, J.S. Lee, A.C. Taylor, S. Sprenger (2010), The toughness of epoxy polymers and fibre composites modified with rubber microparticles and silica nanoparticles, Journal of Materials Science 45, 1193-1210.

[9] M. García, G. van Vliet, S. Jain, B.A.G. Schrauwen, A. Sarkissov, W.E. van Zyl, B. Boukamp (2004), Polypropylene/Silica nanocomposites with improved mechanical properties, Reviews on advanced materials science 6, 169-175.

[10] O.K. Semakina, D, A.N. Phomenko, A.A. Leonteva, I.E. Rymanova (2015), Research of surface properties of fillers for polymers, Procedia Chemistry 15, 79-83.

[11] X. Xu, B. Li, H. Lu, Z. Zhang, H. Wang (2007), The interface structure of nano-Silica/PA66 composites and its influence on material's mechanical and thermal properties Applied Surface Science 254, 1456-1462.
[12] X. Li, Z. Cao, Z. Zhang, H. Dang (2006), Surface-modification in situ of nano-Silica and its structure and tribological properties, $A p$ plied Surface Science 252, 7856-7861.

[13] Ch. Chen, M. Khobaib, D. Curliss (2003), Epoxy layered-silicate nanocomposites, Progress in Organic Coatings 47, 376-383.

[14] M. Sabzi, S.M. Mirabedini, J. Zohuriaan-Mehr, M. Atai (2009), Surface modification of $\mathrm{TiO}_{2}$ nano-particles with silane coupling agent and investigation of its effect on the properties of polyurethane composite coating, Progress in Organic Coatings 65, 222- 228.

[15] L.N. Yashchenko, V.N. Tereshchenko, T.T. Todosiichuk (2013), Nanocomposites based on silicon dioxide. Preparation and properties, Polymer Science Series D 6, 96-102.

[16] Applied plastics engineering handbook. Processing, Materials, and Applications, Second Edition. Edited by Myer Kutz: Elsevier Inc.; 2017.

[17] T. Zemfira, E. Milanovskiy (2015), The contact angle of wetting of the solid phase of soil before and after chemical modification. Eurasian Journal of Soil Science 4, 191-197.

[18] K.G. Marinova, D. Christova, S. Tcholakova, E. Efremov, N.D. Denkov (2005), Hydrophobization of Glass Surface by Adsorption of Poly(dimethylsiloxane) Langmuir 21, 11729-11737.

[19] M. Miwa, A. Nakajima, A. Fujishima, K. Hashimoto, T. Watanabe (2000), Effects of the Surface Roughness on Sliding Angles of Water Droplets on Superhydrophobic Surfaces, Langmuir 16 (2000) 5754-5760

[20] M. Psarski, J. Marczak, J. Grobelny, G. Celichowski (2014), Superhydrophobic Surface by Replication of Laser Micromachined Pattern in Epoxy/Alumina Nanoparticle Composite, Journal of Nanomaterials 2014 Article ID 547895

[21] A. Dong, H. Wu, X. Fan, Q. Wang, Y. Yu, A. Cavaco-Paulo (2016), Enzymatic hydrophobization of jute fabrics and its effect on the mechanical and interfacial properties of jute/PP composites, Express Polymer Letters 10 (5) 420-429.

[22] Y.Lin, L. Wang, J.W. Krumpfer, J.J. Watkins, T.J. McCarthy (2013) Hydrophobization of Inorganic Oxide Surfaces Using Dimethylsilanediol, Langmuir 29, 1329-1332.

[23] M. Norek A. R. Krasinski (2015), Controlling of water wettability by structural and chemical modification of porous anodic alumina (PAA): Towards super-hydrophobic surfaces, Surface and Coatings Technology 276, 464-470. 